\title{
Joint Statement by the Surgery Journal Editors Group: Adopted by the Annals of Surgical Oncology
}

\author{
Mark S. Roh, $\mathrm{MD}^{1}$ and Kelly M. McMasters, $\mathrm{MD}, \mathrm{PhD}^{2}$ \\ ${ }^{1}$ Department of Surgery, UF Health Cancer Center - Orlando Health, Orlando, FL; ${ }^{2}$ The Hiram C. Polk, Jr., MD \\ Department of Surgery, University of Louisville, School of Medicine, Louisville, KY
}

The Annals of Surgical Oncology supports the Joint Statement by the Surgery Journal Editors Group regarding sex-inclusive biomedical and clinical research. ${ }^{1}$ The Surgery Journal Editors Group is composed of editors from 74 international, surgery-related journals who meet once a year at the annual meeting of the American College of Surgeons and discuss concerns common among surgery journals. The following statement was modified from the original by the Editorial Board of Annals of Surgical Oncology to clarify the policy for our authors.

\section{JOINT STATEMENT BY THE SURGERY JOURNAL EDITORS GROUP}

We believe that conducting sex-inclusive biomedical and clinical research is imperative to improving health outcomes of men and women. Note that the word "sex" is being used rather than "gender." Sex is the genotype by which one is born, and gender is the phenotype. It is the chromosomal sex of the human, animal, tissue, or cell to which we are referring. Recent studies have shown that the majority of biomedical research in the field of surgery and related topics is conducted on male animals and male cells, even when studying diseases prevalent in women. ${ }^{2}$ Human clinical research suffers from a lack of sex-based reporting and sex-based analysis of the results. ${ }^{3,4}$ Given these findings, the National Institutes of Health has now asked that sex be considered as a biologic variable in all National Institutes of Health-funded research. ${ }^{5}$ There are two issues: sex-based reporting and analysis. We require sex-based reporting and analysis for all human and animal studies. If only one sex is studied, the authors must include a justification statement as to why a single-sex study was conducted. For tissue and cell studies, the sexual derivation of tissues or cells must be reported when it is known or should be known; sex-based analysis of results must be performed whenever possible.

\section{REFERENCES}

1. Joint statement by the Surgery Journal Editors Group. Am J Surg. 2018. https://doi.org/10.1016/j.amjsurg.2018.05.013.

2. Yoon DY, Mansukhani NA, Stubbs VC, Helenowski IB, Woodruff TK, Kibbe MR. Sex bias exists in basic science and translational surgical research. Surgery. 2014;156(3):508-16.

3. U.S. Government Accountability Office. National Institutes of Health: Better oversight needed to help ensure continued progress including women in health research. https://www.gao.gov/produc ts/GAO-16-13. Published: Oct 22, 2015. Publicly Released: Oct 23, 2015.

4. Mansukhani NA, Yoon DY, Teter KA, Stubbs VC, Helenowski IB, Woodruff TK, Kibbe MR. Determining if sex bias exists in Human Surgical Clinical Research. JAMA Surg. 2016;151(11):1022-30.

5. National Institutes of Health. Consideration of Sex as a Biological Variable in NIH-funded Research. https://grants.nih.gov/grants/g uide/notice-files/NOT-OD-15-102.html. Published June 9, 2015.

\footnotetext{
*While it is not required that every tissue and cell study must include both female and male tissues or cells, researchers should consider sex as a biologic variable in design of their studies.
}

(C) Society of Surgical Oncology 2018

First Received: 11 June 2018;

Published Online: 3 July 2018

K. M. McMasters, MD, PhD

e-mail: mcmasters@louisville.edu 